\title{
Third-Day Oxygenation Index is an Excellent Predictor of Survival in Children Mechanically Ventilated for Acute Respiratory Distress Syndrome
}

This article was published in the following Dove Press journal: Risk Management and Healthcare Policy

\author{
Snežana Rsovac' \\ Katarina Milošević \\ Davor Plavec (iD ${ }^{2,3}$ \\ Dušan Todorović (iD ${ }^{4}$ \\ Ljiljana Šćepanović ${ }^{4}$
}

'Department of Pediatric and Neonatal Intensive Care, University Children's Hospital "Tiršova”, Faculty of Medicine, University of Belgrade, Belgrade, Serbia; ${ }^{2}$ Srebrnjak Children's Hospital, Zagreb, Croatia; ${ }^{3}$ Medical Faculty Osijek, JJ Strossmayer University of Osijek, Osijek, Croatia; ${ }^{4}$ Institute of Medical Physiology "Richard Burian", Faculty of Medicine, University of Belgrade, Belgrade, Serbia

Correspondence: Dušan Todorović Tel +381642739534

Email t.dusan@hotmail.com
Purpose: The aim of this study was to assess the association between oxygenation index (OI) and outcome in children with acute respiratory distress syndrome (ARDS).

Patients and Methods: Patients (age, $>30$ days) in the pediatric intensive care unit from April 2011 to March 2016 with ARDS and who were mechanically ventilated were included. Patients were divided into two age groups: infants $(<12$ month) and older children. Lowest $\mathrm{PaO}_{2} / \mathrm{FiO}_{2}$ and $\mathrm{SpO}_{2} / \mathrm{FiO}_{2}$ ratios and highest mean airway pressure (MAP) were recorded on the first day of ARDS and after $72 \mathrm{~h}$. OI was calculated on the first and third days of mechanical ventilation (MV) and its association with OI (first and third days) and short-term mortality evaluated at 28 days.

Results: MV was initiated a mean of 2.3 days after admission (median, 1.0 day; maximum 14 days). The average MV duration for all patients was 11.8 (median, 7.0) days. Mean (95\% confidence interval (CI)) OI values on the first day of MV were 14.17 (11.94-16.41), 12.72 (10.68-14.75), and 13.24 (11.73-14.74) for infants, older children, and all participants, respectively. In survivors $(n=39)$ mean OI was 11.66 (9.64-13.68) compared with 15.22 (13.03-17.40) in non-survivors $(n=31)$. Logistic regression analysis revealed that OI on day 3 had highly significant prognostic value for mortality (odds ratio, 256.5, 95\% CI 27.1-2424, $\mathrm{p}<0.001$ ), with an AUC of 0.919 (cut-off value, 17; positive predictive value, 0.905; negative predictive value, 0.964; $\mathrm{p}=0.0001)$. In contrast, OI on day 1 did not have significant prognostic value (AUC, 0.634; $\mathrm{p}=0.056$ ) for short-term mortality. Different modes of MV were not significantly associated with outcome $(\mathrm{p}>0.05)$.

Conclusion: OI is a simple, highly accurate, and sensitive predictor of the survival (shortterm mortality) of children mechanically ventilated for ARDS.

Keywords: mortality, respiration, artificial, prognosis, intensive care units, pediatric, blood gas analysis, survivors mortality of children mechanically ventilated for ARDS

\section{Introduction}

Acute respiratory distress syndrome (ARDS) is an acute, diffuse, inflammatory lung injury caused by diverse pulmonary and non-pulmonary etiologies. The "Berlin" criteria are commonly used to diagnose ARDS in clinical practice. ${ }^{1}$ The Pediatric Acute Lung Injury Consensus Conference (PALICC) offered a new definition of Pediatric acute respiratory syndrome (PARDS). ${ }^{2}$ The prevalence of ARDS in children in the United States, Europe, and Australia is 2-12.8 cases/100,000 per year. $^{3}$ Pediatric acute respiratory distress syndrome has lower mortality than adult ARDS. ${ }^{4}$ The short-term mortality - such as 28 - to 60-day mortality remain an 
objective, easily obtained and patient-centered outcome. ${ }^{4}$ The parameter, oxygenation index $(\mathrm{OI}=$ mean airway pressure $(\mathrm{MAP}) \times$ fraction of inspired oxygen $\left(\mathrm{FiO}_{2}\right)$ $\times 100$ /partial pressure of oxygen in arterial blood $\left(\mathrm{PaO}_{2}\right)$ ) is used to evaluate the severity of respiratory failure in children. We hypothesized that, together with other variables, early OI could be a good predictor of outcome (short-term mortality) in children with ARDS. Therefore, we assessed the predictive power of early OI values for short-term survival in children ventilated for ARDS by analyzing the association between early OI (on the first and third days after admission) and short-term (during 28 days) mortality of children ventilated for ARDS.

\section{Patients and Methods}

This was a retrospective study, conducted in our pediatric intensive care unit (PICU) from April 2011 to March 2016. All 70 included children, who ranged from 1 month to 7 years of age, were diagnosed with ARDS using the PALICC criteria (timing within 7 days of known clinical insult, chest imaging findings of new infiltrate consistent with pulmonary parenchymal disease, oxygenation, PARDS severity groups stratified by OI). ${ }^{2}$ Exclusion criteria were: patients who needed inhaled nitric oxide were not included in this analysis, patients younger than 12 months. We also included children older than 1 month on invasive mechanical ventilation with ARDS. Sepsis was defined using the criteria of the Surviving Sepsis Campaign 2012. ${ }^{5}$ We measured non-invasive and invasive blood pressure (Nihon and Carescape monitors), level of lactates (Makler), and urine output in all patients. All patients with severe and moderate PARDS were treated with protective conventional mechanical ventilation (CMV) (tidal volumes/plateau pressure limitations; tidal volumes $5-8 \mathrm{~mL} / \mathrm{kg}$ predicted body weight or $3-6 \mathrm{~mL} / \mathrm{kg}$ predicted body weight for patients with poor respiratory system compliance, inspiratory plateau pressure limit of 28 $\mathrm{cmH}_{2} \mathrm{O}$ ) or high-frequency oscillatory ventilation (HFOV). ${ }^{2}$ Ventilators used for MV were as follows: for CMV, Acutronic Fabian, Drager VN500 and Servo Maquet; for HFOV, SensoMedic type A and Acutronic Fabian. All patients underwent the following analyses: chest radiography, echocardiography was performed by cardiologists who are present 24/7 in our cardiac intensive care unit, blood chemistry, gas analysis (Makler), biochemical analysis of C-reactive protein, monitoring of vital parameters (Nihon and Carescape monitors), and BW measurement on admission. All procedures performed in studies involving human participants were in accordance with the ethical standards of the Ethical Committee of Medical Faculty, University of Belgrade (No. 61206-5210/4-15) and were conducted in accordance with the Declaration of Helsinki. As this was a retrospective study that used anonymized patient data from the medical records, the Ethics Committee considered that there was no need for a post hoc written consent from parents/caregivers.

Our main objective was the evaluation of OI as a predictor of survival/short-term mortality. All patients were treated with CMV on the first day and then HFOV or CMV, depending on arterial blood gas analysis, OI, and clinical parameters. Patients with a deterioration of gas analysis to $20 \%$ of the initial values for $\mathrm{PaO}_{2}, \mathrm{PaCO}_{2}$, $\mathrm{O}_{2}$ saturation, and $\mathrm{pH}$ in arterial blood sample, or other parameters for ARDS (chest radiography, decreasing $\mathrm{PaO}_{2}$ $/ \mathrm{FiO}_{2}$ ratio), were converted to a $\mathrm{HFOV}$, while patients without changes continued to be ventilated by CMV. All patients were divided into two groups by age: infants $(<12$ months old) and children up to 7 years of age. Drug treatments included sedation (fentanyl, 1-2 $\mu \mathrm{g} / \mathrm{kg} / \mathrm{h}$ ) and inotropic stimulation (dopamine, 5-20 $\mu \mathrm{g} / \mathrm{kg} / \mathrm{min}$; milrinone, $0.25-0.75 \mu / \mathrm{kg} / \mathrm{min}$; adrenaline, $0.01-1 \mu \mathrm{g} / \mathrm{kg} / \mathrm{min}$ ), as required. Antibiotics were prescribed for all patients. OI was calculated using the $\mathrm{FiO}_{2}$ (from a blood sample analyzed on a GEM 3000 Makler instrument), MAP (value automatically calculated by the ventilator) and $\mathrm{PaO}_{2}$ (from a blood sample analyzed on a GEM 3000 Makler instrument) on the first day of admission to our PICU and 24h, $48 \mathrm{~h}$ and $72 \mathrm{~h}$ after MV. Outcome was classified as survival or death, censored at 28 days after admission.

Data were analyzed using the SPSS statistical software program (IBM SPSS Statistics v23). All p values $<0.05$ were considered statistically significant. Categorical data are presented as frequency and ratio (\%) and continuous variables as mean and standard deviation (SD), mean and $95 \%$ confidence interval $(95 \% \mathrm{CI})$, or median and range, depending on the normality of the distribution. Univariable and multivariable logistic regression analyses were conducted to identify significant associations between the outcome (survival/death; short-term mortality at 28 days) and the following factors: sex, age, BW percentile, mod of MV after $1 \mathrm{~h}$, mod of MV after $72 \mathrm{~h}$, heart failure, sepsis, kidney failure, tracheostomy, pneumothorax, and atelectasis. Factors with $\mathrm{p}$ values $\leq 0.1$ on univariable analysis were included in multivariable analysis. Results are expressed as estimates of relative risk (odds ratio; OR) 
with 95\% CI. Receiver operating characteristic (ROC) curves were constructed for OI on the first and third days of MV, and adequate cut-off values were determined as predictors of outcome. Logistic regression was used to determine the statistical significance of associations between outcome and OI cut-off values, and to assess the sensitivity and specificity of these parameters for outcome prediction. The cut-off value for OI on the first day was (14, and that on the third day was 17). A Cox proportional hazard model was used to determine the effect of the following factors on time to outcome (death): sex, age, BW percentile, mod of MV after $1 \mathrm{~h}$, mod of MV after 72 $\mathrm{h}$, OI on the first day (cut-off value, 14), OI on the third day (cut-off value, 17), cardiovascular weakness, sepsis, kidney failure, tracheostomy, lung overpressure injury, and atelectasis. Kaplan-Meier analysis was used to estimate the survival function from lifetime data, depending on the value of OI on the third day (cut-off value, 17).

\section{Results}

Seventy children with ARDS were included in this study. Patient characteristics and clinical parameters at baseline and at initiation of MV are summarized in Table 1. The mean time of MV initiation was 2.3 days after admission (median, 1.0 day; maximum 14 days). The average duration of MV for all patients was 11.8 days (median 7.0 days). Ventilator-free days (at 28 days) in survivors were $16.3 \pm 6.1$. The average OI value on day 1 of MV was 14.01 (SD, 5.34) and on day 3 of MV was 16.41 (SD, 8.82). The average $\mathrm{pH}$ value on day 1 of $\mathrm{MV}$ was 7.21 (7.10-7.33), $\mathrm{PaCO}_{2}$ was $56 \mathrm{mmHg}(41-67)$ and $\mathrm{PaO} 2$ was $52 \mathrm{mmHg}$ (45-67) (median 25-75\%).

Analysis of the association of patient characteristics with modes of MV by univariable and multivariable analyses indicated that male sex (OR 3.255, 95\% CI 1.093-9.692, $\mathrm{p}=0.034)$ and absence of shock (OR 0.14, 95\% CI, 0.044-0.476, $\mathrm{p}<0.001$ ) were significant predictors of short-term mortality (Table 2). Analysis of OI on the first and third days of MV revealed that OI on the third day of MV was a highly significant predictor of mortality (OR, 256.5, 95\% CI 27.1-2424, $\mathrm{p}<0.001$; positive predictive value, 0.905; negative predictive value, 0.964) (Table 3).

ROC curve analysis was used to assess the individual performance of OI to predict in-ICU mortality. OI on the first day of MV did not show good predictive performance for mortality $(\mathrm{AUC}=0.634, \mathrm{p}=0.056$ ), whereas OI
Table I Baseline Demographics and Clinical Parameters of Patients Treated with Mechanical Ventilation for Acute Respiratory Distress Syndrome $(\mathrm{N}=70)$

\begin{tabular}{|c|c|c|c|}
\hline \multirow{4}{*}{$\begin{array}{l}\text { Variable } \\
\text { Sex }\end{array}$} & \multirow{2}{*}{\multicolumn{2}{|c|}{$\begin{array}{l}\text { Frequency } \\
n\end{array}$}} & \multirow{4}{*}{$\begin{array}{l}\% \\
57.1 \\
42.9\end{array}$} \\
\hline & & & \\
\hline & Male & 40 & \\
\hline & Female & 30 & \\
\hline \multirow[t]{2}{*}{ Body weight percentile } & $<\mathrm{PIO}$ & 12 & 17.1 \\
\hline & $>P I 0$ & 58 & 82.9 \\
\hline \multirow[t]{2}{*}{ Blood culture } & Positive & 25 & 35.7 \\
\hline & Negative & 45 & 64.3 \\
\hline \multirow{2}{*}{$\begin{array}{l}\text { Hypoxemia at beginning of } \\
\text { MV }\end{array}$} & $<200$ & 38 & 54.3 \\
\hline & $<300$ & 18 & 25.7 \\
\hline \multirow{2}{*}{$\begin{array}{l}\text { Hypoxemia after I h of } M V \\
(20 \% \text { change) }\end{array}$} & Yes & 27 & 38.6 \\
\hline & No & 43 & 61.4 \\
\hline \multirow[t]{2}{*}{ Hypoxemia after $24 \mathrm{~h}$ of $\mathrm{MV}$} & $<200$ & 38 & 54.3 \\
\hline & $<300$ & 9 & 12.9 \\
\hline \multirow[t]{2}{*}{ Hypoxemia after $72 \mathrm{~h}$ of $\mathrm{MV}$} & $<200$ & 32 & 45.7 \\
\hline & $<300$ & 15 & 21.4 \\
\hline \multirow[t]{2}{*}{ Mod of MV after $72 h$} & CMV & 49 & 70.0 \\
\hline & HFOV & 21 & 30.0 \\
\hline \multirow[t]{4}{*}{$\mathrm{pH}$} & $<7.3$ & 48 & 68.6 \\
\hline & $7.3-7.4$ & 21 & 30.0 \\
\hline & (normal) & & \\
\hline & $>7.4$ & 1 & 1.4 \\
\hline \multirow[t]{3}{*}{$\mathrm{PaCO}_{2}(\mathrm{mmHg})$} & $<35$ & 5 & 7.1 \\
\hline & $35-45$ (normal) & 20 & 28.6 \\
\hline & $>45$ & 45 & 64.3 \\
\hline \multirow[t]{2}{*}{$\mathrm{PaO}_{2}(\mathrm{mmHg})$} & $<60$ & 50 & 71.4 \\
\hline & $>60$ & 20 & 28.6 \\
\hline Variable & $\begin{array}{l}\text { Median } \\
(25-75 \%)\end{array}$ & & \\
\hline pH & $7,21(7,10-7,33)$ & & \\
\hline $\mathrm{PaCO}_{2}(\mathrm{mmHg})$ & $56(4 I-67)$ & & \\
\hline $\mathrm{PaO}_{2}(\mathrm{mmHg})$ & $52(45-67)$ & & \\
\hline Primary etiologies & & $\mathbf{n}$ & $\%$ \\
\hline Pneumonia & & 28 & 40.0 \\
\hline Sepsis & & 21 & 30.0 \\
\hline Aspiration & & 8 & 11.4 \\
\hline Concomitant cardiac disease & & 5 & 7.2 \\
\hline Other clinical conditions & & 8 & 11.4 \\
\hline $\begin{array}{l}\text { Ventilation setting at } 0 \\
\text { hours }^{\mathrm{a}}(\text { Mean } \pm \text { SD; Median } \\
(25-75 \%))\end{array}$ & CMV & & HFOV \\
\hline PEEP $\left(\mathrm{cmH}_{2} \mathrm{O}\right)$ & $4.47 \pm 1.37$ & & \\
\hline
\end{tabular}

(Continued) 
Table I (Continued).

\begin{tabular}{|c|c|c|}
\hline \multirow[t]{2}{*}{ Variable } & Frequency & \multirow[t]{2}{*}{$\%$} \\
\hline & $\mathbf{n}$ & \\
\hline PIP $\left(\mathrm{cmH}_{2} \mathrm{O}\right)$ & $22.70 \pm 3.62$ & \\
\hline MAP $\left(\mathrm{cmH}_{2} \mathrm{O}\right)$ & $11.96 \pm 2.42$ & \\
\hline $\mathrm{FiO}_{2}$ & $0.84 \pm 0.24$ & $0.98 \pm 0.06$ \\
\hline $\begin{array}{l}\text { Frequency: (CMV - breaths/ } \\
\text { min; HFOV - Hz) }\end{array}$ & $22(19-24)$ & $7(6-7)$ \\
\hline CDP $\left(\mathrm{cmH}_{2} \mathrm{O}\right)$ & & $24.00 \pm 1.92$ \\
\hline$\Delta \mathrm{P}\left(\mathrm{cmH}_{2} \mathrm{O}\right)$ & & $40.76 \pm 3.72$ \\
\hline
\end{tabular}

Notes: ${ }^{a} 0$ hour means the initiation of CMV or HFOV.

Abbreviations: $\mathrm{MV}$, mechanical ventilation; $\mathrm{CMV}$, conventional mechanical ventilation; HFOV, high-frequency oscillatory ventilation; $\mathrm{PaCO}_{2}$, partial pressure of carbon dioxide in arterial blood; $\mathrm{PaO}_{2}$, partial pressure of oxygen in arterial blood; TV, tidal volume; PEEP, positive expiratory pressure; PIP, peak inspiratory pressure; MAP, mean airway pressure; $\mathrm{FiO}_{2}$, inspiratory fraction of oxygen; CDP, continuous distending pressure; $\Delta \mathrm{P}$, amplitude. value on the third day after MV showed strong predictive power for mortality of patients with ARDS (AUC $=0.919$, $\mathrm{p}<0.001$ ) (Figures 1 and 2). Also, OI in the first day and $\mathrm{OI}$ in the third day analyzed based on PALICC criteria (OI in the first day cut-off $=14.30, \mathrm{AUC}=0.634,95 \% \mathrm{CI}$, $0.504-0.764$; OI value on the third-day cut-off $=17.10$, 95\% CI, 0.838-1.000) (Table 4). The best cut-off values for first and third-day OI were 14 and 17, respectively. Kaplan-Meier survival analysis comparison of children divided into two subgroups based on the third-day OI cutoff value demonstrated that median survival in the group with third-day OI values $\geq 17$ was 6 days (interquartile range, 5-7 days) (Figure 3). To further assess the association of different factors with survival time, we conducted Cox regression analysis, which showed that BW

Table 2 Association of Patient Characteristics and Mode of Mechanical Ventilation with the Main Outcome (Short-Term Mortality) Using Univariable and Multivariable Analyses

\begin{tabular}{|c|c|c|c|c|c|c|c|c|c|}
\hline \multirow[t]{2}{*}{ Variable } & \multicolumn{3}{|c|}{ Outcome } & \multicolumn{3}{|c|}{ Univariable Analysis } & \multicolumn{3}{|c|}{ Multivariable Analysis } \\
\hline & & Survival $(n=39)$ & Death $(n=31)$ & OR & $95 \% \mathrm{Cl}$ & $P$ value & OR & $95 \% \mathrm{Cl}$ & $P$ value \\
\hline Sex & $\begin{array}{l}\text { Male } \\
\text { Female }\end{array}$ & $\begin{array}{l}27(67.5 \%) \\
12(40.0 \%)\end{array}$ & $\begin{array}{l}13(32.5 \%) \\
18(60.0 \%)\end{array}$ & 2.803 & $0.863-9.110$ & 0.086 & 3.255 & $1.093-9.692$ & 0.034 \\
\hline Age & $\begin{array}{l}<1 \text { year } \\
>1 \text { year } \\
X \pm S D\end{array}$ & $\begin{array}{l}23(62.2 \%) \\
16(48.5 \%) \\
2.1 \pm 2.6\end{array}$ & $\begin{array}{l}14(37.8 \%) \\
17(51.5 \%) \\
2.4 \pm 2.3\end{array}$ & 0.912 & $0.235-3.543$ & 0.894 & & & \\
\hline BW percentile & $\begin{array}{l}<\mathrm{PIO} \\
>\mathrm{PIO}\end{array}$ & $\begin{array}{l}5(41.7 \%) \\
34(58.6 \%)\end{array}$ & $\begin{array}{l}7 \text { (58.3\%) } \\
24 \text { (41.4\%) }\end{array}$ & 0.637 & $0.131-3.093$ & 0.576 & & & \\
\hline Mod of MV day I & $\begin{array}{l}\text { CMV } \\
\text { HFOV }\end{array}$ & $\begin{array}{l}30(61.2 \%) \\
9(42.9 \%)\end{array}$ & $\begin{array}{l}19(38.8 \%) \\
12(57.1 \%)\end{array}$ & 1.825 & $0.428-7.788$ & 0.417 & & & \\
\hline Mod of MV day 3 & $\begin{array}{l}\text { CMV } \\
\text { HFOV }\end{array}$ & $\begin{array}{l}30(61.2 \%) \\
9(42.9 \%)\end{array}$ & $\begin{array}{l}19(38.8 \%) \\
12(57.1 \%)\end{array}$ & 1.825 & $0.428-7.788$ & 0.417 & & & \\
\hline Shock & $\begin{array}{l}\text { Yes } \\
\text { No }\end{array}$ & $\begin{array}{l}17(39.5 \%) \\
22(81.5 \%)\end{array}$ & $\begin{array}{l}26(60.5 \%) \\
5(18.5 \%)\end{array}$ & 0.175 & $0.04 I-0.758$ & 0.020 & 0.14 & $0.044-0.476$ & $<0.001$ \\
\hline Sepsis & $\begin{array}{l}\text { Yes } \\
\text { No }\end{array}$ & $\begin{array}{l}6(33.3 \%) \\
33(63.5 \%)\end{array}$ & $\begin{array}{l}12(66.7 \%) \\
19(36.5 \%)\end{array}$ & 0.936 & $0.185-4.734$ & 0.936 & & & \\
\hline
\end{tabular}

Notes: Male sex and the absence of shock were statistically significant predictors of short-term survival in children with ARDS treated with mechanical ventilation (univariable and multivariable logistic regression analyses).

Abbreviations: BW, body weight; MV, mechanical ventilation; CMV, conventional mechanical ventilation; HFOV, high-frequency oscillatory ventilation; OR, odds ratio; Cl, confidence interval.

Table 3 Association of OI Values with the Main Outcome (Short-Term Mortality)

\begin{tabular}{|c|c|c|c|c|c|c|c|c|c|c|}
\hline Variable & & Survival $(n=39)$ & Death $(n=3 I)$ & OR & $95 \% \mathrm{Cl}$ & $P$ value & Sensitivity & Specificity & PPV & NPV \\
\hline Ol day I & $<14$ & $20(55.6 \%)$ & $16(44.4 \%)$ & 0.987 & $0.384-2.535$ & 0.978 & 0.513 & 0.484 & 0.556 & $0.44 I$ \\
\hline Cut-off & $\geq 14$ & 19 (55.9\%) & 15 (44.1\%) & & & & & & & \\
\hline Ol day 3 & $<17$ & 38 (90.5\%) & $4(9.5 \%)$ & 256.5 & $27 . I-2424$ & $<0.001$ & 0.974 & 0.871 & 0.905 & 0.964 \\
\hline Cut-off & $\geq 17$ & I (3.6\%) & 27 (96.4\%) & & & & & & & \\
\hline
\end{tabular}

Notes: Third-day oxygenation index was a statistically significant predictor of short-term mortality in children with ARDS treated with mechanical ventilation (multivariable analysis). Abbreviations: Ol, oxygenation index; OR, odds ratio; $\mathrm{Cl}$, confidence interval; PPV, positive predictive value; NPV, negative predictive value. 


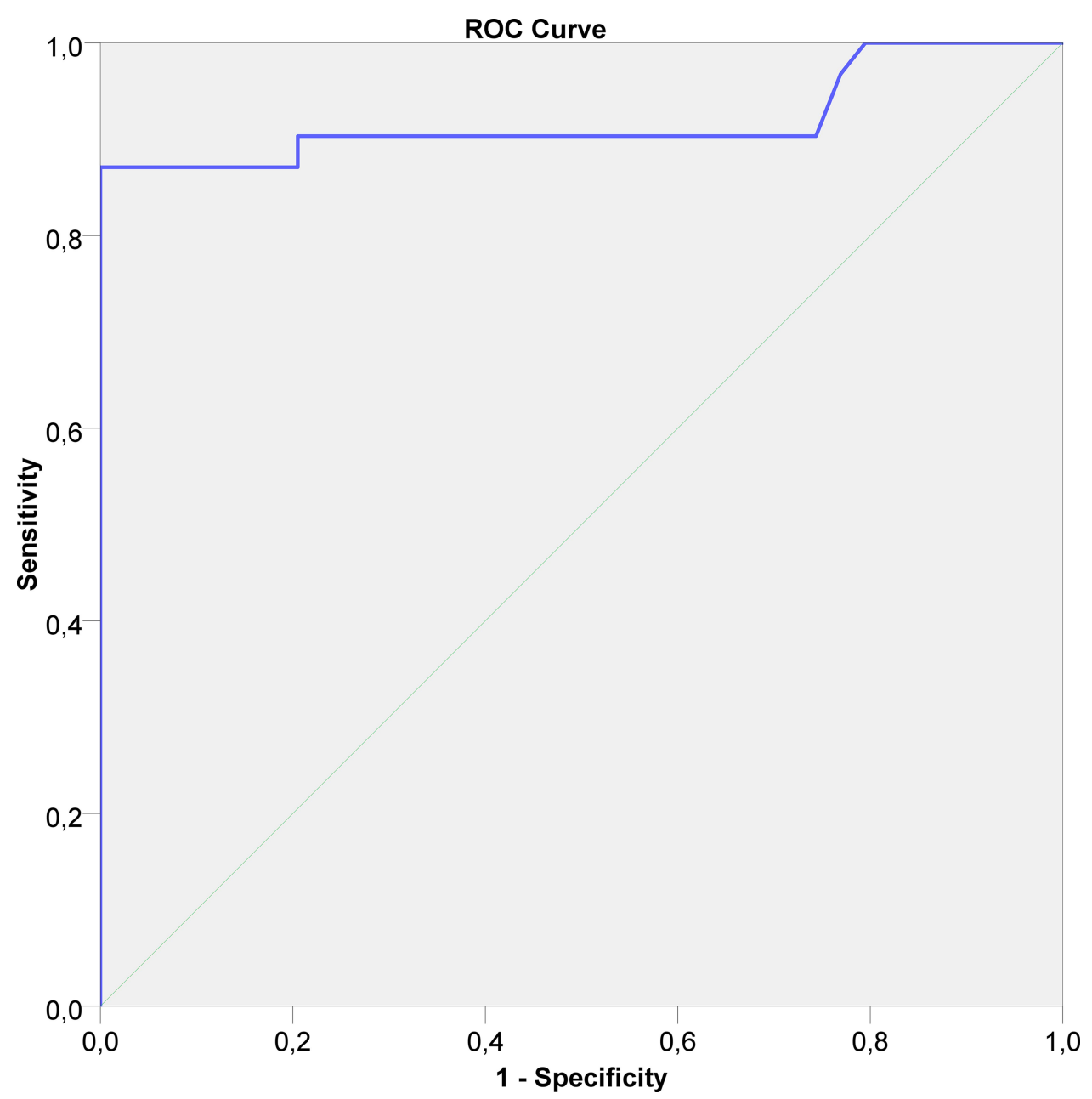

Figure I ROC analysis of first-day oxygenation index for prediction of short-term mortality (cut-off $=14.30, \mathrm{AUC}=0.634,95 \% \mathrm{Cl}, 0.504-0.764, \mathrm{P}=0.056$ )

$<10$ th percentile, third-day $\mathrm{OI} \geq 17$, and sepsis were significant predictors of survival time (Table 5 ).

\section{Discussion}

In our study, values of OI on the third day of MV showed that it was a highly significant predictor of mortality, with higher values significantly increasing the likelihood of early death. Important indicators of early mortality besides third-day OI $(\mathrm{p}<0.0001)$ were $\mathrm{BW}<10$ th percentile $(p=0.019)$ and sepsis $(p=0.023)$ diagnosed after PARDS. Significant predictors of mortality in PARDS are immunocompromised state, multiorgan failure, older age, and severity of hypoxemia. ${ }^{6}$ Our pediatric patients with ARDS had a high mortality rate of $44.28 \%$, all of them were on invasive mechanical ventilation; mortality was among those who were severe PARDS (33\% [54 of 165; 95\% CI 26-41]) in the study of Khemani et al. ${ }^{7}$ Erikson et al reported mortality of $30 \%$ in pediatric patients with acute lung injury (ALI). ${ }^{3}$ Flori et al reported a similar mortality rate for patients with ARDS and multiple organ failure, ${ }^{8}$ as did Gupta et al. ${ }^{9}$ Wong et al reported a lower mortality rate in a study that compared the Berlin and Pediatric Acute Lung Injury Consensus Conference (PALICC) criteria for patients with ARDS and in comparison to Berlin definition, the PALICC criteria identified more number of patients with ARDS. ${ }^{10}$ The PALICC criteria recognize oxygenation index as the main parameter of lung disease severity in defining pediatric ARDS. ${ }^{2}$ Hammond et $\mathrm{al}^{11}$ analyzed data from 397 children and founded that OI>16 was a cut-off value for severe ARDS; our results were similar to those findings. Khemani et al examined OI at PARDS onset, mortality increased substantially at an OI of 15 , corresponding with the PALICC severe group. ${ }^{7}$ In our study the cut-off values for OI on the first and third days were 14 and 17, respectively. Yehya et al founded increasing mortality with 


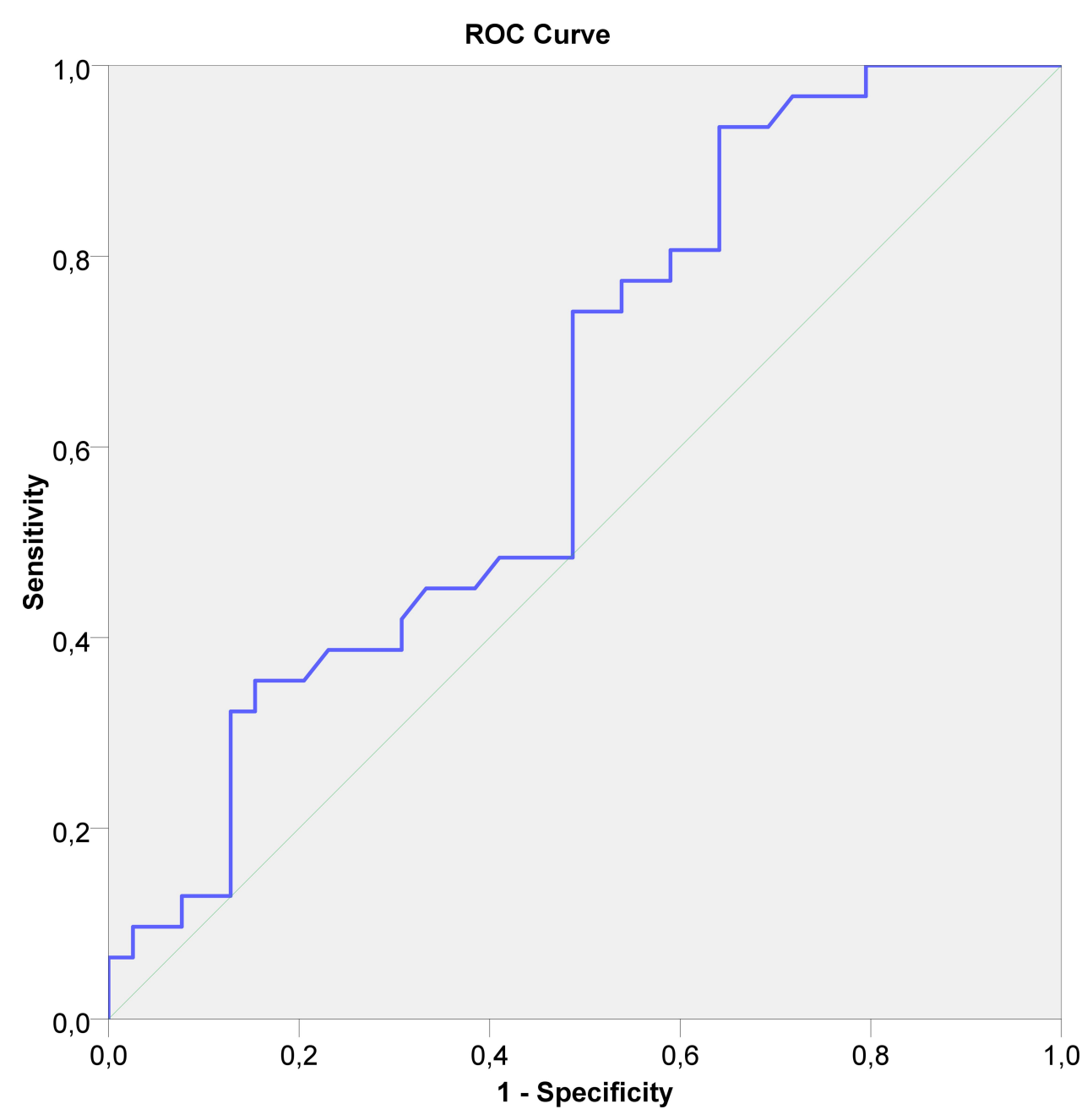

Figure 2 ROC analysis of third-day oxygenation index for prediction of short-term mortality (cut-off $=17.10, \mathrm{AUC}=0.919,95 \% \mathrm{Cl}, 0.838-1.000, \mathrm{P}<0.00 \mathrm{I}$ ).

worsening oxygenation, from 6 to 24 hours. ${ }^{12}$ Our results about mortality are similar, we found increasing OI on the third day of mechanical ventilation and mortality. Hammond et al reported a retrospective, single-center study evaluating the association between mortality and maximum OI during MV. ${ }^{11}$ The authors reported a mortality rate of $6-7 \%$ among patients with maximum
$\mathrm{OI}<17$, compared with $18 \%$ among those with a maximum OI $>17$. In our study, the mean OI on the first day for all children was $14.011 \pm 5.3444$ and on the third day was $16.414 \pm 8.820$. Ferguson et al reported a high mortality rate in children on HFOV with high values of OI $(>17) .{ }^{13}$ We converted children with $\mathrm{OI}>17$ on the first day from CMV to HFOV; however, there was no

Table 4 Prediction of Short-Term Survival in Children with ARDS Based on PALICC Criteria

\begin{tabular}{|c|c|c|c|c|c|c|}
\hline \multirow[t]{2}{*}{ Variable } & \multicolumn{3}{|l|}{ Outcome } & \multicolumn{3}{|c|}{ Univariable Analysis } \\
\hline & & Survival $(n=39)$ & Death $(n=3 I)$ & OR & $95 \% \mathrm{Cl}$ & $P$ value \\
\hline PALICC score (first day) & $\begin{array}{l}\text { Mild }(\mathrm{OI}=4-8) \\
\text { Moderate }(\mathrm{OI}=8-16) \\
\text { Severe }(\mathrm{OI}>16)\end{array}$ & $\begin{array}{l}6(100.0 \%) \\
21(52.5 \%) \\
12(50.0 \%)\end{array}$ & $\begin{array}{l}0(0.0 \%) \\
19(47.5 \%) \\
12(50.0 \%)\end{array}$ & 0.571 & $0.123-2.665$ & 0.476 \\
\hline PALICC score (third day) & $\begin{array}{l}\text { Mild }(\mathrm{OI}=4-8) \\
\text { Moderate }(\mathrm{OI}=8-16) \\
\text { Severe }(\mathrm{OI}>16)\end{array}$ & $\begin{array}{l}7(100.0 \%) \\
30(88.2 \%) \\
2(6.9 \%)\end{array}$ & $\begin{array}{l}0(0.0 \%) \\
4(11.8 \%) \\
27(93.1 \%)\end{array}$ & $|26.25|$ & 18.209-875.370 & $<0.001$ \\
\hline
\end{tabular}




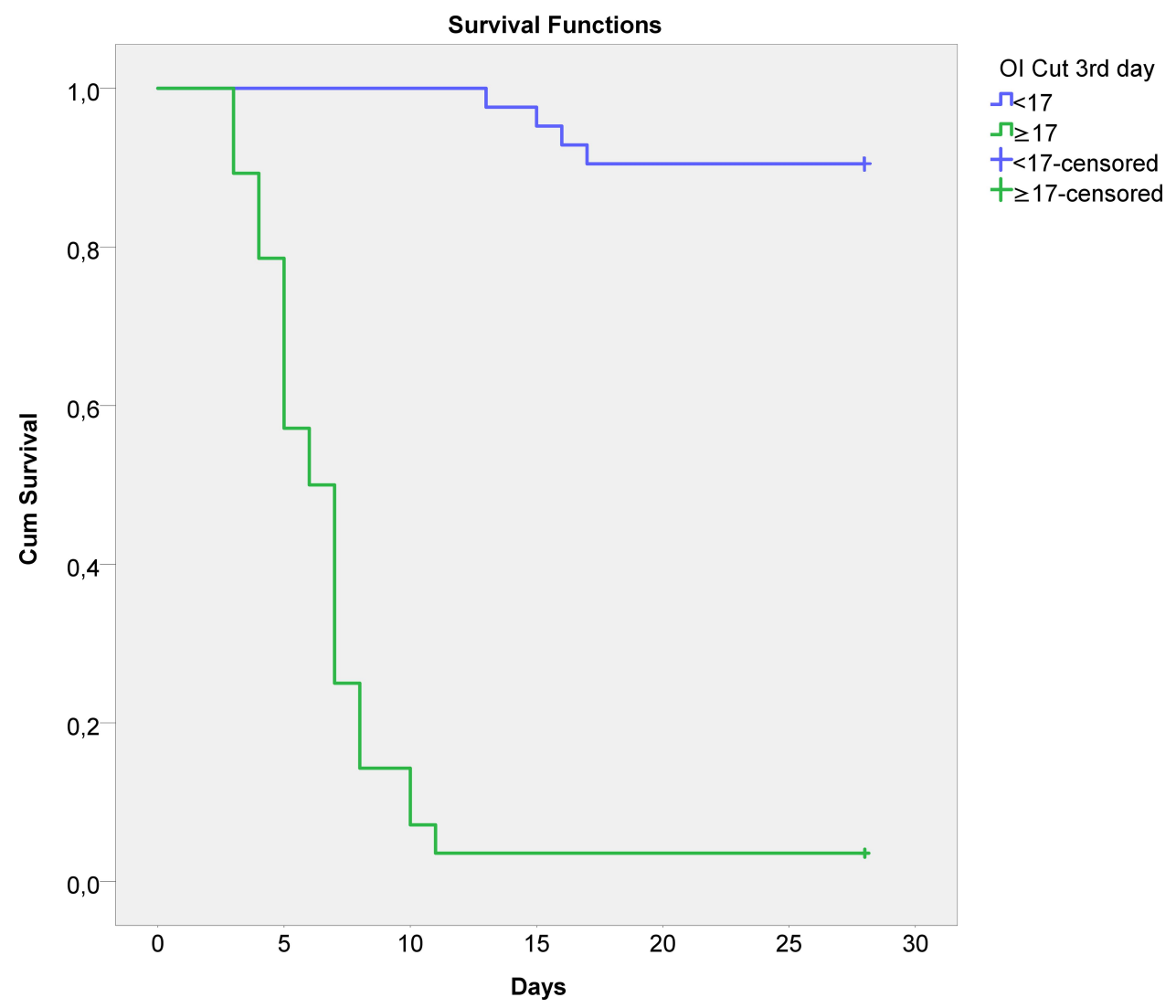

Figure 3 Kaplan-Meier survival curves for third-day oxygenation index values $<$ and $\geq 17$.

difference in outcome between children on CMV and HFOV. Wong et al reported no significant difference between any respiratory indices at diagnosis of ALI/

Table 5 Predictors of Short-Term Survival in Children with ARDS Treated with Mechanical Ventilation

\begin{tabular}{|l|l|l|l|}
\hline \multirow{2}{*}{ Variable } & \multirow{2}{*}{ P value } & \multicolumn{2}{|l|}{$95 \%$ Cl } \\
\cline { 3 - 4 } & & Lower & Upper \\
\hline Sex & & 0.579 & 3.415 \\
Age & 0.452 & 0.358 & 2.583 \\
BW <IOth percentile & 0.938 & 1.253 & 12.244 \\
Mod of MV I day & 0.019 & 0.239 & 1.982 \\
OI, first day & 0.489 & 0.343 & 1.914 \\
OI, third day & 0.632 & 29.178 & 850.735 \\
Shock & $<0.0001$ & 0.979 & 14.567 \\
Sepsis & 0.054 & 0.090 & 0.837 \\
Renal failure & 0.023 & 0.695 & 4.810 \\
Tracheostomy & 0.222 & 0.455 & 92.476 \\
Lung overpressure injury & 0.205 & 0.610 & 10.053 \\
Atelectasis & 0.754 & 0.469 & 2.847 \\
\hline
\end{tabular}

Notes: BW percentile, third-day oxygenation index and sepsis were significant predictors of short-term survival in children with ARDS treated with mechanical ventilation (multivariable analysis; Cox proportional hazard model).

Abbreviations: $\mathrm{Cl}$, confidence interval; $\mathrm{BW}$, body weight; $\mathrm{MV}$, mechanical ventilation; Ol, oxygenation index.
ARDS among survivors and non-survivors. ${ }^{14}$ High OI and low $\mathrm{P} / \mathrm{F}$ ratio $24 \mathrm{~h}$ after diagnosis of ARDS were associated with mortality and, from day 3 onward, OI could differentiate patients with increased mortality. ${ }^{14}$ Here, we identified correlations of OI values on the first and third days with an increased likelihood of early death.

Calculating OI presents a potential problem, because some studies have used MAP, while others used plateau inspiratory airway pressure. We used MAP to calculate OI because our ventilators can only calculate this parameter. Dechert et al used plateau pressure, because it includes the effect of positive endexpiratory pressure at a given tidal volume. ${ }^{15}$

Trachsel et al conducted a prospective study of children with acute hypoxemic respiratory failure and reported an association between poor outcome and a high OI in the first $12 \mathrm{~h}$ of MV. ${ }^{16}$ Further, Slaczka et al reported that OI is a simple and sensitive predictor of survival of infants with pulmonary hypoplasia and pulmonary hypertension. ${ }^{17}$

The major limitation of our study was the small sample size, because of our limited ward capacity; hence, a multicenter study, including more hospitals in our country is needed. Also, different procedural management of children with ARDS in other hospitals could yield 
different results. Future studies should be planned with more frequent OI measurement, including use of the PALICC criteria and age-dependent OI.

\section{Conclusion}

Our data indicate that OI on the third day of MV, together with BW (percentile) and sepsis, is a simple, sensitive, and accurate predictor of the survival of children with ARDS on MV.

\section{Acknowledgments}

University Children's hospital in Belgrade, Serbia.

\section{Disclosure}

Prof. Dr. Davor Plavec reports grants, personal fees from GlaxoSmithKline; personal fees, non-financial support from Menarini, Philips, and Revenio; personal fees from Pliva, Boehringer Ingelheim, Belupo, Novartis, MSD, and Chiesi, outside the submitted work. The authors report no other conflicts of interest in this work.

\section{References}

1. Ranieri VM, Rubenfeld GD, Thompson BT, et al.; ARDS Definition Task Force. Acute respiratory distress syndrome: the Berlin definition. JAMA. 2012;307(23):2526-2533.

2. The Pediatric Acute Lung Injury Consensus Conference Group. Pediatric acute respiratory distress syndrome: consensus recommendations from the pediatric acute lung injury consensus conference. Pediatr Crit Care Med. 2015;428-439.

3. Erickson S, Schibler A, Numa A, et al.; Paediatric Study Group. Australian and New Zealand Intensive Care Society. Acute lung injury in pediatric intensive care in Australia and New Zealand: a prospective, multicenter, observational study. Pediatr Crit Care Med. 2007;8(4):317-323.

4. Yehya N, Thomas NJ. Relevant outcomes in pediatric acute respiratory distress syndrome studies. Front Pediatr. 2016;4:51. doi:10.3389/ fped.2016.00051

5. Dellinger RP, Levy MM, Rhodes A, et al. Surviving sepsis campaign: international guidelines for management of severe sepsis and septic shock: 2012. Crit Care Med. 2013;41(2):580-637. doi:10.1097/ CCM.0b013e31827e83af
6. Orloff KE, Turner DA, Rehder KJ. The current state of pediatric acute respiratory distress syndrome. Pediatr Allergy Immunol Pulmonol. 2019;32(2):35-44. doi:10.1089/ped.2019.0999

7. Khemani RG, Smith L, Lopez-Fernandez YM, et al. Paediatric acute respiratory distress syndrome incidence and epidemiology (PARDIE): an international, observational study. Lancet Respir Med. 2018;7:115-128. doi:10.1016/S2213-2600(18)30344-8

8. Flori HR, Glidden DV, Rutherford GW, et al. Pediatric acute lung injury: prospective evaluation of risk factors associated with mortality. Am J Respir Crit Care Med. 2005;171(9):995-1001. doi:10.1164/rccm.200404-544OC

9. Gupta S, Sankar J, Lodha R, et al. Comparison of prevalence and outcomes of pediatric acute respiratory distress syndrome using pediatric acute lung injury consensus conference criteria and Berlin definition. Front Pediatr. 2018;6:93. doi:10.3389/ fped.2018.00093

10. Wong JJ, Jit M, Sultana R, et al. Mortality in pediatric acute respiratory distress syndrome: A systematic review and meta-analysis. J Intensive Care Med. 2019;34(7):563-571. doi:10.1177/08850666 17705109

11. Hammond BG, Garcia-Filion P, Kang P, et al. Identifying an oxygenation index threshold for increased mortality in acute respiratory failure. Respir Care. 2017;62(10):1249-1254. doi:10.4187/respcare. 05092

12. Yehya N, Thomas NJ, Khemani RG, et al. Risk stratification using oxygenation in the first 24 hours of pediatric acute respiratory distress syndrome. Crit Care Med. 2018;46:619-624. doi:10.1097/CCM.000 0000000002958

13. Ferguson ND, Cook DJ, Guyatt GH, et al. High frequency oscillatory in early acute respiratory distress syndrome. $N$ Engl J Med. 2013;368 (9):795-805. doi:10.1056/NEJMoa1215554

14. Wong JJ, Loh TF, Testoni D, et al. Epidemiology of pediatric acute respiratory distress syndrome in Singapore: risk factors and predictive respiratory indices for mortality. Front Pediatr. 2014;2:78. doi:10.3389/fped.2014.00078

15. Dechert RE, Park PK, Bartlett RHJ. Evaluation of the oxygenation index in adult respiratory failure. Trauma Acute Care Surg. 2014;76 (2):469-473. doi:10.1097/TA.0b013e3182ab0d27

16. Trachsel D, McCrindle BW, Nakagawa S, et al. Oxygenation index predicts outcome in children with acute hypoxemic respiratory failure. Am J Respir Crit Care Med. 2005;172:206-211. doi:10.116 4/rccm.200405-625OC

17. Basiewicz-Slaczka E, Wołoszczuk-Gebicka B, Yaqoub S, et al. The value of the oxygenation index in the prediction of postnatal outcome in neonates with congenital diaphragmatic hernia. Preliminary report. Dev Period Med. 2015;19(3 Pt 1):283-288.
Risk Management and Healthcare Policy

\section{Publish your work in this journal}

Risk Management and Healthcare Policy is an international, peerreviewed, open access journal focusing on all aspects of public health, policy, and preventative measures to promote good health and improve morbidity and mortality in the population. The journal welcomes submitted papers covering original research, basic science, clinical \& epidemiological studies, reviews and evaluations, guidelines, expert opinion and commentary, case reports and extended reports. The manuscript management system is completely online and includes a very quick and fair peer-review system, which is all easy to use. Visit http://www.dovepress.com/testimonials.php to read real quotes from published authors. 